\title{
Role of toll receptors in diabetic nephropathy
}

\author{
Mona Mansour ${ }^{1}$, Randa Fayez Salam ${ }^{1 *}$, Lila Rashed ${ }^{2}$, Heba Salam $^{1}$ \\ ${ }^{1}$ Internal Medicine Department, Cairo University, Cairo, Egypt; *Corresponding Author: randa.salam@live.com \\ ${ }^{2}$ Medical Biochemistry Department, Cairo University, Cairo, Egypt \\ Received 4 September 2013; revised 4 October 2013; accepted 12 October 2013 \\ Copyright (c) 2014 Mona Mansour et al. This is an open access article distributed under the Creative Commons Attribution License, \\ which permits unrestricted use, distribution, and reproduction in any medium, provided the original work is properly cited. In accor- \\ dance of the Creative Commons Attribution License all Copyrights (c) 2014 are reserved for SCIRP and the owner of the intellectual \\ property Mona Mansour et al. All Copyright (C) 2014 are guarded by law and by SCIRP as a guardian.
}

\section{ABSTRACT}

Objectives: Diabetic nephropathy is the leading cause of chronic kidney disease. The pathogenesis of DN remains incompletely understood. It has been recently demonstrated that inflammatory processes play a significant role in the development and progression of DN. Toll-like receptors play a fundamental role in the innate immune system by triggering proinflammatory signaling pathways. Our aim is to evaluate the expression of TLRs on monocytes and relate their expression with inflammation in HD patients with \& without diabetic nephropathy. Method: In a case control study (60) patients from Alkasr El Aini Hospital on hemodialysis were divided into two groups: Group 1, 30 patients on heamodialysis not due to diabetic nephropathy, Group 2, 30 patients on heamodialysis due to diabetic nephropathy, compared to Group 3, including 30 healthy controls. All participants were subjected to: Full medical history, complete physical examination, Serum creatinine, uric acid, A1C, fundus examination, detection of TLR2, TLR expression by real time PCR in peripheral blood mononuclear cells. Data were statically calculated using SPSS, comparision between groups was done using student $T$ test comparing 2 groups, correlation using spearman's correlation. Results: Diabetic had significantly increased TLR2, TLR4 mRNA in peripheral blood mononuclear cells compared to controls and non diabetics patient on heamodialysis $(p<0.001)$, TLR2, TLR4 significantly correlated with dialysis duration in diabetic $(p<$ 0.001 ), no correlation with $A 1 C$ in relation to TLR2 $(p=0.078)$, TLR4 $(p=0.163)$. Conclusion: TLR2, TLR4 were significantly elevated in diabetic on dialysis initiating event in the patho- genesis of DN, providing a link between hyperglycemia and hypoxia with inflammation and fibrosis within the kidney. Hence, therapeutic interventions aimed at targeting the inflammatory component through interruption of TLR signaling may be a novel strategy to target prevention and treatment of $D N$.

\section{KEYWORDS}

Diabetic Nephropathy; Toll Receptor 2, 4

\section{INTRODUCTION}

Diabetic nephropathy has become the most common cause of end stage renal disease (ESRD) in developed countries, which is mainly due to the increasing prevalence of Type 2 diabetes [1]. Although DN is traditionally viewed as a non-immune disease, emerging evidence suggests that inflammatory mechanisms play an important role in disease pathogenesis and progression.

Indeed, the decline of renal function in diabetic patients with proteinuria is positively associated with tubulointerstitial inflammation [2].

From a therapeutic perspective, blockade of the reninangiotensin system coupled to strictglycemic and blood pressure control is the best documented treatment strategy for DN.

Besides, the initial promises shown in early clinical trials, indicate many patients still progress relentlessly to ESRD [2].

Therefore, investigations into the mechanisms underlying intrarenal inflammation may provide new therapeutic targets for anti-inflammatory strategies against DN.

Toll-like receptors (TLRs) are a conserved family of pattern recognition receptors that play a fundamental role in the innate immune system by triggering proinflammatory signaling pathways in response to microbial pathogens. In addition, TLRs are also activated by endogenous 
agonists of no microbial origin and are involved in noninfectious inflammatory conditions [3].

Recently, TLRs have been implicated in the pathogenesis of acute and chronic renal disorders. [4]

Among the 11 human TLRs, TLR4 and/or TLR2 might be a molecular link between inflammation and diabetes as they promote tubulointerstitial inflammation during diabetic nephropathy [5].

Therefore we intend to study the relation and the levels of TLR2 and TLR4 in end stage diabetic nephropathy.

\section{PATIENTS AND METHODS}

\subsection{Population of Study \& Disease Condition}

90 Patients from Kasr El Ani University Hospital on hemodialysis (HD) due to diabetic nephropathy, patients non-diabetic nephropathy \& group of healthy people. All participants are divided into three groups: Group 1, 30 patients on heamodialysis not due to diabetic nephropathy, Group 2, 30 patients on heamodialysis due to diabetic nephropathy \& Group 3, 30 participants including healthy control.

\subsection{Exclusion Criteria}

Patients receiving statins, or having cancer or autoimmune disease or recently hospitalized for infectious diseases.

\subsection{Methodology in Details}

All patients underwent full medical history, complete physical examination, Funds examination to all participants of Group 2, Serum creatinine, BUN, CRP, HbA1c, Membrane expression of TLR2 and TLR4.

Serum creatinine and blood urea. Glycosaylated hemoglobin

Detection of TLR2\&TLR4 gene expression by real time-PCR: Three $\mathrm{ml}$ peripheral venous blood was withdrawn by clean venipuncture on EDTA vacutainer tubes from cases as well as 20 healthy volunteers Plasma and serum samples were separated by immediate centrifugation at $4^{\circ} \mathrm{C}$ (1500 g for $\left.10 \mathrm{~min}\right)$, aliquoted and stored at $-80^{\circ} \mathrm{C}$ until analysis.

Isolation of mononuclear cells from whole blood was performed through use of Ficoll-Paque Premium (Biochrom, Berlin, Germany).

\section{-RNA Extraction:}

Total RNA was extracted from cell pellet using SV Total RNA Isolation System kit, Promega, MadisonVVI, USA.

It was designed for isolation of total intranuclear RNA from fresh, whole blood treated anticoagulated with
EDTA.

Quantitation and Storage of RNA:

*To determine the concentration and purity of RNA, absorbance at $260 \mathrm{~nm}$ and $280 \mathrm{~nm}$ was measured in a spectrophotometer.

cDNA Synthesis:

The extracted RNA was reverse transcribed into cDNA using: AMV Reverse Transcriptase, Promega, and Madison. VVI, USA

\section{qPCR (quantitative real time PCR)}

Statistical methodology

Data were statistically calculated using SPSS, comparision between groups was done using student t test, correlation using spearman's correlation

\section{RESULTS}

90 Patients from Kasr El Ani University Hospital on hemodialysis due to diabetic nephropathy, patients nondiabetic nephropathy\& group of healthy people. All participants are divided into three groups: Group 1, 30 patients on heamodialysis not due to diabetic nephropathy, Group 2, 30 patients on heamodialysis due to diabetic nephropathy \& Group 3, 30 participants including healthy control (Table 1 showing Demographic and laboratory: data of patients and control groups).

There is statistically significant correlation between level of TLR2 in end stage diabetic nephropathy compared to end stage non diabetic nephropathy and control group (Figure 1).

There is statistically significant correlation between level of TLR4 in end stage diabetic nephropathy compared to end stage non diabetic nephropathy and control groups (Figure 2).

Table 1. Demographic and laboratory data of patients and control groups.

\begin{tabular}{cccc}
\hline & $\begin{array}{c}\text { Group 1 } \\
\text { (non-DM) }\end{array}$ & $\begin{array}{c}\text { Group 2 } \\
\text { (DM) }\end{array}$ & $\begin{array}{c}\text { Control } \\
\text { group }\end{array}$ \\
\hline AGE & $50.8 \pm 11.22$ & $56 \pm 10.9$ & $42.1 \pm 4.8$ \\
SEX M/F & $17 / 13$ & $17 / 13$ & $30 / 0$ \\
D/HDx & $5.4 \pm 3.39$ & $1.7 \pm 1.6$ & \\
Associated diseases & & & \\
*HTN & $73.3 \%$ & $80 \%$ & $0 \%$ \\
*IHD & $33.3 \%$ & $20 \%$ & $0 \%$ \\
*Both & $13.3 \%$ & $30 \%$ & \\
Cr (mg/dl) & $\mathbf{1 1 . 0 8} \pm \mathbf{2 . 2 6}$ & $\mathbf{9 . 8} \pm \mathbf{2 . 6}$ & $\mathbf{1 . 0 8} \pm \mathbf{0 . 2 8}$ \\
Urea (mg/d) & $\mathbf{1 8 0 . 0} \pm \mathbf{3 9 . 6}$ & $\mathbf{1 6 8 . 7} \pm \mathbf{4 8 . 9}$ & $\mathbf{3 2 . 9} \pm \mathbf{5 . 9}$ \\
HbA1c \% & $\mathbf{4 . 6 \%} \pm \mathbf{0 . 4} \%$ & $\mathbf{7 . 2 \%} \pm \mathbf{0 . 7} \%$ & $\mathbf{3 . 4 5} \pm \mathbf{0 . 6 5 \%}$ \\
TLR2 & $\mathbf{0 . 2 8} \pm \mathbf{0 . 1 6}$ & $\mathbf{1 . 1 8} \pm \mathbf{0 . 5 4}$ & $\mathbf{0 . 1 5} \pm \mathbf{0 . 0 6}$ \\
TLR4 & $\mathbf{0 . 5} \pm \mathbf{0 . 2}$ & $\mathbf{2 . 1 3} \pm \mathbf{0 . 9}$ & $\mathbf{0 . 4} \pm \mathbf{0 . 1 4}$ \\
\hline
\end{tabular}

$\mathrm{D} / \mathrm{HDx}$ (duration of heamodyalysis ) 


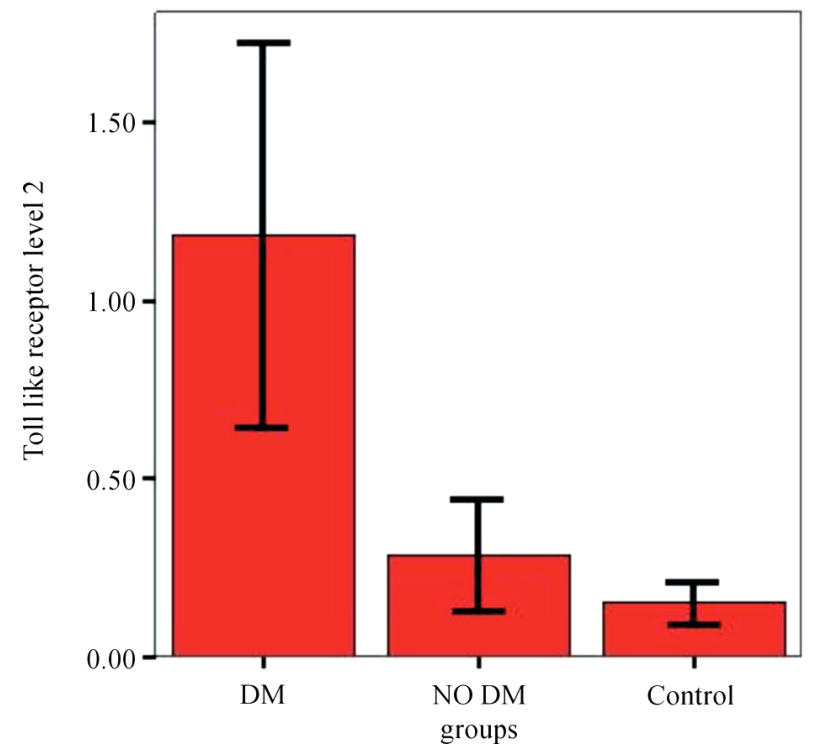

Figure 1. Comparison Group 1 (non-DM), Group 2 (DM) \& Group 3 (control group) as regarding the level of toll like receptors 2 .

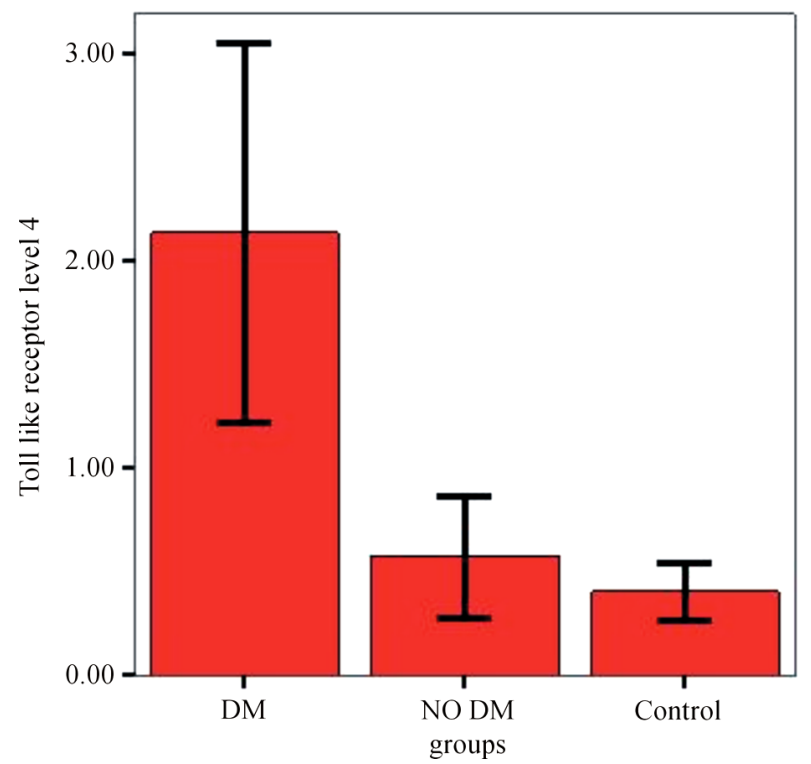

Figure 2. Comparison Group 1 (non-DM), Group 2 (DM) \& Group 3 (control group) as regarding the level of toll like receptors 4 .

Correlation between toll-like receptors with different clinical and laboratory data, showing a correlation between the duration of hemodialysis and TLR2 and TLR4 $(\mathrm{r}=0.661, \mathrm{p}=0.001),(\mathrm{r}=0.5, \mathrm{p}=0.003)$ respectively which is statistically significant.

The correlation between glycosaylated hemoglobin and TLR2 and TLR4 is $(r=0.169, \mathrm{p}=0.372)$ and $(\mathrm{r}=$ $0.231, \mathrm{p}=0.219$ ) respectively which is not statistically significant shown in Table 2.

The correlation between the duration of diabetes and
TLR2 and TLR4 is $(r=0.147, p=0.734)$ and $(r=0.111$, $\mathrm{p}=0.559)$ respectively which is not statistically significant.

There is correlation between the duration of hemodialysis and TLR2 and TLR4 $(r=0.83, p=0.0001)$ and $(r=$ $0.712, \mathrm{p}=0.1$ ) respectively which is statistically significant.

The correlation between glycosaylated hemoglobin and TLR2 and TLR4 is $(r=0.326, p=0.078)$ and $(r=$ $0.261, \mathrm{p}=0.163)$ respectively which is not statistically significant (results shown in Table 3 ).

There is statistically significant correlation between level of TLR2 and duration of hemodialysis in end stage diabetic nephropathy compared to end stage non diabetic nephropathy shown in Figure 3.

There is statistically significant correlation between level of TLR4 and duration of hemodialysis in end stage diabetic nephropathy compared to end stage non diabetic nephropathy shown in Figure 4.

\section{DISCUSSION}

Diabetes has become the most common single cause of end-stage renal disease worldwide, this is due to the facts that:

- Diabetes, particularly Type 2, is increasing in prevalence.

- Diabetes patients now live longer.

About $20 \%-30 \%$ of patients with Type 1 or 2 diabetes develop evidence of nephropathy, but in Type 2 dia-

Table 2. Toll like receptors correlation with different clinical/laboratory data in Group 1 (non-DM).

\begin{tabular}{ccccc}
\hline \multirow{2}{*}{ clinical/laboratory data } & \multicolumn{2}{c}{ TLR2 } & \multicolumn{2}{c}{ TLR4 } \\
\cline { 2 - 5 } & $\mathbf{r}$ & $\mathbf{p}$ & $\mathbf{r}$ & $\mathbf{p}$ \\
\hline age & -0.106 & 0.579 & 0.091 & 0.632 \\
D/HDx & 0.661 & 0.001 & 0.523 & 0.003 \\
Cr (mg/dl) & -0.335 & 0.071 & -0.154 & 0.416 \\
Urea (mg/dl) & 0.270 & 0.149 & 0.324 & 0.08 \\
HbA1c\% & 0.169 & 0.372 & 0.231 & 0.219 \\
\hline
\end{tabular}

Table 3. Toll like receptors correlation with different clinical/ laboratory data in Group 2 (DM).

\begin{tabular}{ccccc}
\hline \multirow{2}{*}{ clinical/laboratory data } & \multicolumn{2}{c}{ TLR2 } & \multicolumn{2}{c}{ TLR4 } \\
\cline { 2 - 5 } & $\mathbf{r}$ & $\mathbf{p}$ & $\mathbf{r}$ & $\mathbf{p}$ \\
\hline AGE & 0.278 & 0.137 & -0.299 & 0.108 \\
D/DM & 0.147 & 0.437 & 0.111 & 0.559 \\
D/HDx & 0.832 & 0.001 & 0.712 & 0.001 \\
Cr (mg/dl) & 0.110 & 0.564 & 0.92 & 0.630 \\
Urea (mg/dl) & -0.062 & 0.746 & 0.022 & 0.906 \\
HbA1c\% & 0.326 & 0.078 & 0.261 & 0.163 \\
\hline
\end{tabular}



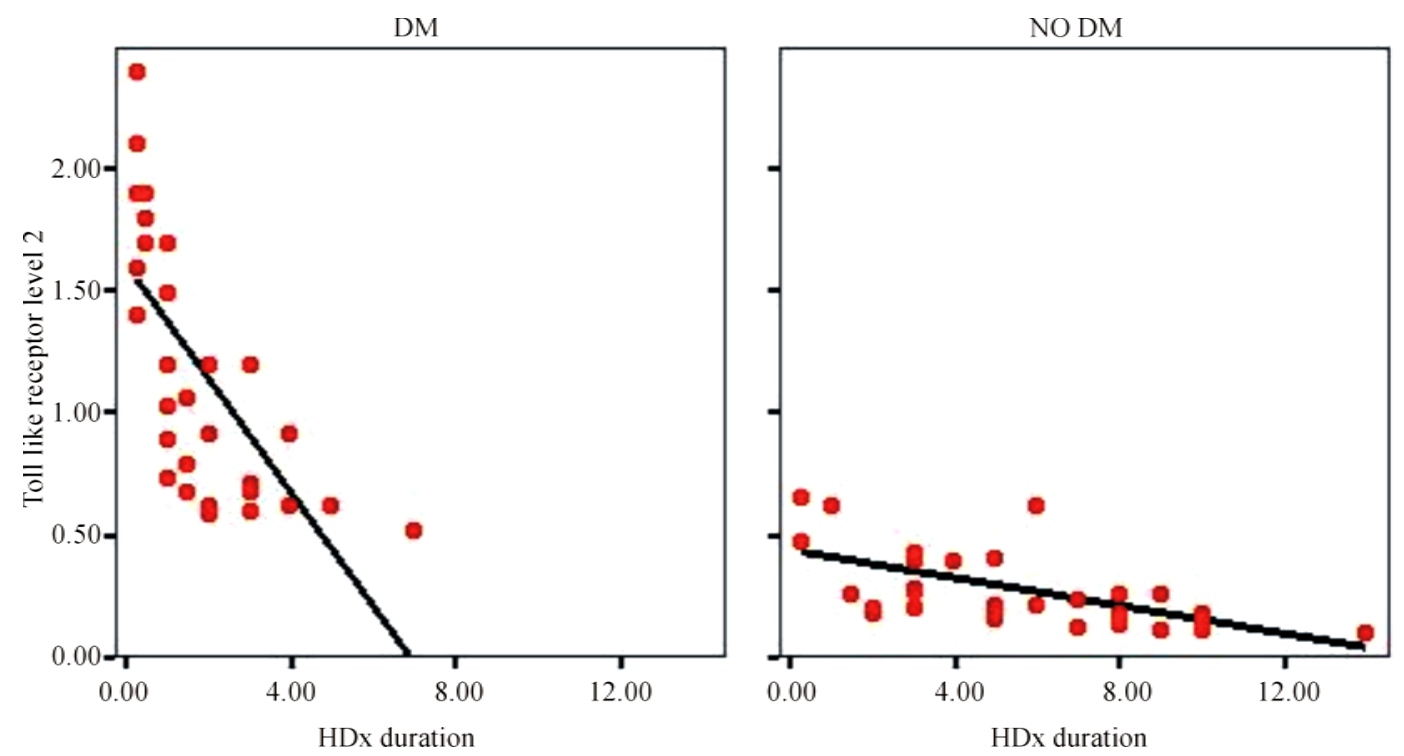

Figure 3. Correlation of TLR2 and duration of hemodialysis.
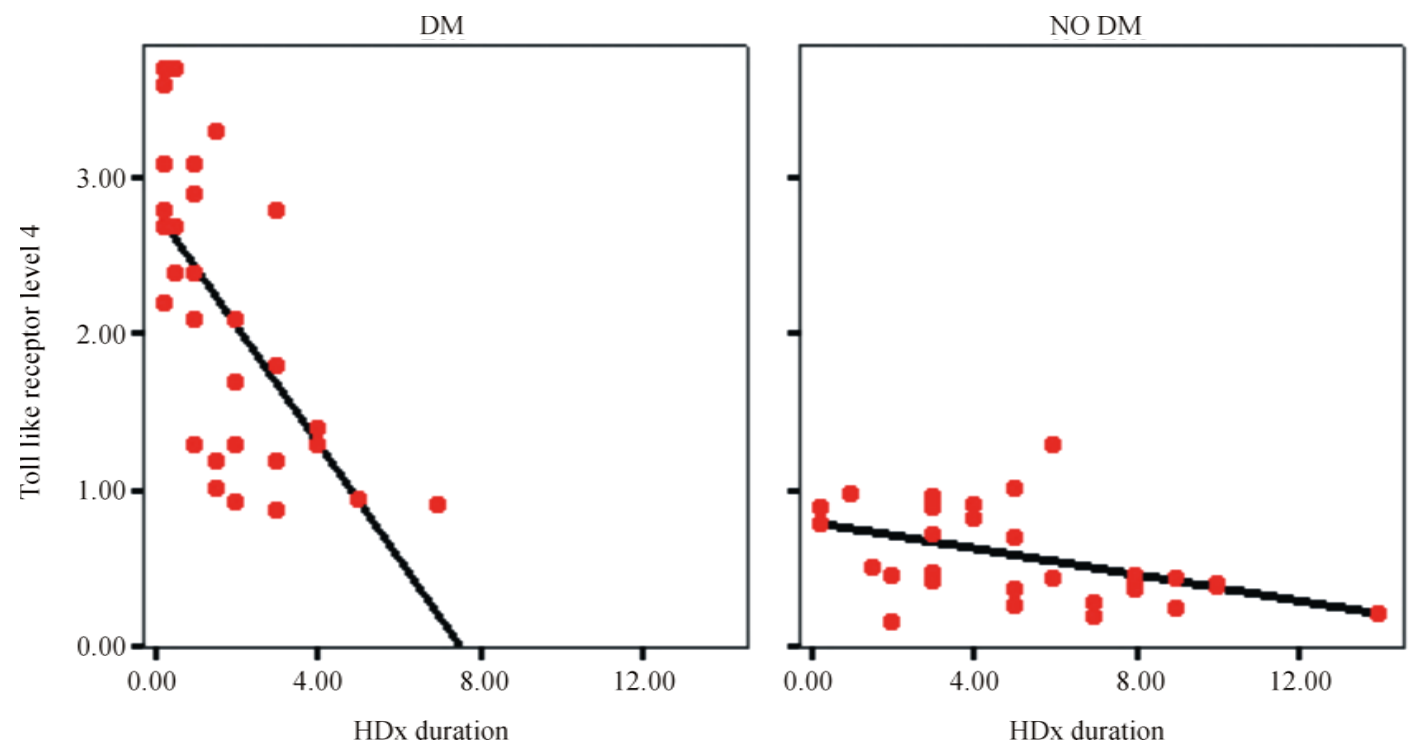

Figure 4. Correlation of TLR4 and duration of hemodialysis.

betes, a considerably smaller fraction of this progress to end stage renal disease (ESRD).

However, because of much greater prevalence of Type 2 diabetes, such patients constitute over half of those diabetic patients currently starting on dialysis [6].

Diabetes Mellitus is a major risk factor for heart, kidney diseases, and lower limb amputations. Emerging in vitro and in vivo data suggest that systemic inflammation plays a role in the pathogenesis of diabetes mellitus complications via innate immune receptors. Mainly nephropathy [7].

Diabetic nephropathy is traditionally viewed as no immune disease; emerging evidence suggests that inflammatory mechanisms play an important role in disease pa- thogenesis and progression. Indeed, the deterioration of renal function in diabetic patients with proteinuria is positively associated with tubulointerstitial inflammation [5].

Inflammatory response is a recognized factor in the pathogenesis of diabetic nephropathy. Numerous experimental and clinical studies have shown the participation of different inflammatory molecules and pathways in the path physiology of this complication [5].

Although albuminuria is widely used and is considered the best marker for renal damage in diabetic patients, certain limitations should be taken into consideration. First, not all patients with proteinuria will develop progressive renal dysfunction [8]. Additionally, 30\% of diabetic patients with renal impairment have normoalbu- 
minuria [9]. Second, the cardiovascular and renal morbidity is elevated in the "high normal" range of UAE [10] Third, a number of variables affecting UAE lack standardization including urine collection methods, reporting of test results, reference intervals for albumin-to-creatinine ratio and lack of a complete reference system for urine albumin and creatinine measurements [10]. Finally, multiple markers of renal dysfunction, either urinary or serum, can appear before the detection of microalbuminuria, suggesting that microalbuminuria occurs once significant kidney damage has already occurred [10].

Toll-like receptors (TLRs) recognize molecular patterns relating to a variety of microbial infections. Stimulation through TLRs leads to activation of antigen-presenting cells, production of inflammatory cytokines creating inflammation, and production of Type 1 interferons (IFNs) that include IFN-alpha and -beta, and exerts direct effects on regulatory cells. These effects can direct the immune response, dealing with the immediate problems of infection and activating more specific responses of the adaptive immune system [11].

The recognition of microbial components by mammalian TLRs plays an important role in the activation of the innate immune response and subsequent proinflammatory reactions. TLRs also interact with ligands generated at sites of injury [12].

TLRs present on the cell surface recognize bacterial and fungal components, whereas intracellular TLRs recognize viral or microbial nucleic acids. In addition, TLRs also interact with endogenous ligands, such as oxLDL (oxidized LDL), HSPs (heat-shock proteins) 60 and 70, fibrinogen and fibronectin, which are also elevated in Diabetes Mellitus [13] Thus different TLRs are amenable to targeting by different types of agents [13].

Among the TLRs, TLR2 and TLR4 play a critical role in the pathogenesis of inflammation and diabetes, in both experimental and clinical conditions [14].

The interactions among increased glucose levels, elevated NEFAs [non-esterified ("free") fatty acids] and resultant pro-inflammatory cytokines in diabetes have clear implications for the immune system [15].

Mohammad et al., 2006 [16,17], (Creely et al., 2007) [15] and (Song et al., 2006) [18] reported increased TLR2 and TLR4 expression in bone marrow-derived macrophages of Type 1 diabetic NOD mice, correlating with increased NF- $\kappa \mathrm{B}$ (nuclear factor $\kappa \mathrm{B}$ ) activation in response to end toxins and increased pro-inflammatory cytokines.

It was reported that the increase in TLR2 and TLR4 expression, intracellular signaling and TLR-mediated inflammation in monocytes has a significant correlation with HbA1c (glycated hemoglobin) levels in diabetic patients. [14]

Also, TLR2 and TLR4 play an important role in athe- rosclerosis. TLR2 and TLR4 bind to components of the gram positive and gram negative bacteria, respectively [19]. They are expressed in multiple cells and tissues, primarily in monocytes. TLR2 and TLR4 expression is increased in atherosclerotic oplaque macrophages and in animal models of atherosclerosis [20].

Our study included 3 groups: Group 1: 30 patients with end stage renal disease on regular hemodialysis due to non-diabetic nephropathy, Group 2: 30 patients with end stage renal disease due to diabetic nephropathy on regular hemodialysis and Group 3: 30 healthy volunteers, Patients receiving satins, or having cancer or autoimmune disease or recently hospitalized for infectious diseases have been excluded.

We aimed in this study to evaluate the expression of TLRs on monocytes and relate their expression with inflammation in hemodialysis patients with \& without diabetic nephropathy.

We took full history of all patients, complete physical examination, fundus examination of all patients, we measure serum creatinine, blood urea, level of HbA1c, level of toll-like receptors 2 and 4.

Our results included that:

- The level of TLRs 2 and 4 was higher in patients with end stage renal disease due to diabetic nephropathy (p $\leq 0.01$ ) than patients with end stage renal disease due to non-diabetic nephropathy and control group.

- The level of TLRs 2 and 4 has no correlation with demographic data of these patients independent on sex and age.

- The level of TLR2 and 4 has no correlation to clini$\mathrm{cal} /$ laboratory data of patients including serum keratinize, blood urea, HbA1c, duration of diabetes mellitus. However, there was positive correlation between the level of TLRs 2 and 4 with duration of hem dialysis $(\mathrm{p} \leq 0.01)$.

This result partially agreed with Xanthi Zikou et al., (2011) [21], his study concluded that chronic kidney disease CKD patients and patients with diabetic nephropathy are characterized by increased expression of TLRs 2 and 4, on monocytes, that may contribute to their increased inflammatory state. He divided the subjects into: Group 1 included 37 CKD patients, not having diabetes mellitus. Group 2 included 19 CKD patients with diabetic nephropathy. Both groups were compared with age matched controls, (control group). His results showed that Patients of Group 1 exhibited increased membrane expression only of TLR2 in monocytes compared with the control group $(\mathrm{p}<0.02)$. Patients of Group 2 presented increased membrane expression of both TLR2 and TLR4 compared with the control group $(\mathrm{p}<0.003$ and $\mathrm{P}$ $<0.001$, respectively) and increased expression of TLR4 compared with Group 1 ( $<<0.02)$.

Our result also, partially agreed with (Miao Lin et al., 
(2012) [22], his study concluded overexpression of TLR4 in the human diabetic kidney suggesting a possible role for TLR4 but not TLR2 in mediating monocot/macrophage recruitment and tubulointerstitial inflammation in diabetic nephropathy. His study was on Kidney biopsy tissues were obtained from nine subjects with Type 2 diabetes and biopsy-proven DN, nine subjects with Type 2 diabetes lacking nephropathy, nine normal control subjects, and nine subjects with no diabetic nephrotic syndrome. His result showed that the Renal Cortical TLR4 but Not TLR2 was elevated and Correlated with Infiltrating CD68+ Monocytes/Macrophages in diabetic nephropathy Biopsies.

Also, our result partially agreed with (Mohan R. et al., (2010) [23], his study concluded that TLR2 and TLR4 expression, their ligands, signaling, and functional activation are increased in recently diagnosed T2DM and contribute to the proinflammatory state. In his study he measured the freshly isolated monocytes from healthy human controls $(n=23)$ and T2DM subjects $(n=23)$ using real time RT PCR, Western blot, and Flow cytometric assays. His result showed that T2DM subjects had significantly increased TLR2, TLR4 mRNA and protein in monocytes compared to controls $(p<0.05)$. This result in his study agreed with our result. However, he showed that this increased TLR2, TLR4 mRNA and protein in monocytes was correlated with HbA1c which did not agree with our result.

Also, our result partially agreed with (Sridevi Devaraj et al., (2011) [24], his study concluded that there is significant role for TLR2 in promoting inflammation and early changes of incipient diabetic nephropathy. His study was on mice, He induced T1DM in TLR2 knockout mice and wild-type littermates using streptozotocin (STZ). Fasting blood, peritoneal macrophages, and kidneys were obtained for flow cytometry, Western blot, microscopy, and cytokine assays at 6 and 14 weeks after induction of diabetes. His result was that Macrophage TLR2 expression and MyD88-dependent signaling were increased in diabetic mice (wild type_STZ) compared with non diabetic wild type mice.

\section{CONCLUSIONS}

Based on our findings that the level of toll-like receptors 2 and 4 is elevated in patients with end stage diabetic nephropathy compared to that of patients with end stage renal disease due to non-diabetic nephropathy, TLRs 2 and 4 are significant serum markers of diabetic nephropathy and play a critical role in pathogenesis of diabetic nephropathy. Thus, we recommend the following:

- We recommend further studies on the Toll-like receptors 2 and 4 to correlate them with the different stages of diabetic nephropathy.
- The use of anti-inflammatory therapeutic agents and their value on the change of the level of Toll-like receptors 2 and 4.

\section{CONFLICT OF INTEREST}

None.

\section{REFERENCES}

[1] Zimmet, P., Alberti, K. and Shaw, J. (2001) Global and societal implications of the diabetes epidemic. Nature, 414, 782-787. http://dx.doi.org/10.1038/414782a

[2] Navarro, J.F., Milena, F.J., Mora, C., Leon, C. and García, J. (2006) Renal pro-inflammatory cytokine gene expression in diabetic nephropathy: Effect of angiotensin-converting enzyme inhibition and pentoxifylline administration. American Journal of Nephrology, 26, 562-570.

http://dx.doi.org/10.1159/000098004

[3] Beutler, B. (2004) Inferences, questions and possibilities in Toll-like receptor signalling. Nature, 430, 257-263. http://dx.doi.org/10.1038/nature02761

[4] Cunningham, P.N., Wang, Y., Guo, R., He, G. and Quigg, R.J. (2004) Role of toll-like receptor 4 in endotoxin-induced acute renal failure. The Journal of Immunology, 172, 2629-2635.

[5] Devaraj, S., Dasu, M.R., Park, S.H. and Jialal, I. (2009) Increased levels of ligands of Toll-like receptors 2 and 4 in Type 1 diabetes. Diabetologia, 52, 1665-1668. http://dx.doi.org/10.1007/s00125-009-1394-8

[6] Mark, E.C., Karim, J.-D. and Merlin, C.T. (2005) Targets to retard the progression of diabetic nephropathy. Kidney International, 68, 1439-1445.

http://dx.doi.org/10.1111/j.1523-1755.2005.00555.x

[7] Ramirez, S.R. and Dasu, M. R.K. (2012) Toll-like receptors and diabetes complications: Recent advances. Current Diabetes Reviews, 8, 480-488. http://dx.doi.org/10.2174/157339912803529887

[8] Campbell, R.C., Ruggenenti, P. and Remuzzi, G. (2002) Halting the progression of chronic nephropathy. Journal of the American Society of Nephrology, 13, S190-S195. http://dx.doi.org/10.1097/01.ASN.0000032522.29672.0A

[9] An, J.H., Cho, Y.M., Yu, H.G., Jang, H.C., Park, K.S., Kim, S.Y. and Lee, H.K. (2009) The clinical characteristics of normoalbuminuric renal insufficiency in Korean Type 2 diabetic patients: A possible early stage renal complication. Journal of Korean Medical Science, 24, S75-S81.

http://dx.doi.org/10.1097/01.ASN.0000032522.29672.0A

[10] Ruggenentim, P. and Remuzzi, G. (2007) Kidney failure stabilizes after a two-decade increase: Impact on global (renal and cardiovascular) health. Clinical Journal of the American Society of Nephrology, 2, 146-150. http://dx.doi.org/10.2215/CJN.02830806

[11] Wong, F.S. and Wen, L. (2008) Toll-like receptors and diabetes. Annals of the New York Academy of Sciences, 1150, 123-132. http://dx.doi.org/10.1196/annals.1447.063 
[12] Uematsu, S. and Akira, S. (2006) Toll-like receptors and innate immunity. Journal of Molecular Medicine, 84, 712-725. http://dx.doi.org/10.1007/s00109-006-0084-y

[13] Chiu, Y. C., Lin, C. Y., Chen, C. P., Huang, K. C., Tong, K.M., Tzeng, C. Y., Lee, T. S., Hsu, H. C. and Tang, C.-H. (2009) Peptidoglycan enhances IL-6 production in human synovial fibroblasts via TLR2 receptor, focal adhesion kinase, Akt, and AP-1- dependent pathway. The Journal of Immunology, 183, 2785-2792. http://dx.doi.org/10.4049/jimmunol.0802826

[14] Dasu, M.R., Devaraj, S., Park, S. and Jialal, I. (2010) Increased toll-like receptor (TLR) activation and TLR ligands in recently diagnosed Type 2 diabetic subjects. Diabetes Care, 33, 861-868. http://dx.doi.org/10.2337/dc09-1799

[15] Schwartz, E.A., Zhang, W.Y., Karnik, S.K., Borwege, S., Anand, V.R., Laine, P.S., Su, Y. and Reaven, P.D. (2010) Nutrient modification of the innate immune response: A novel mechanism by which saturated fatty acids greatly amplify monocyte inflammation. Arteriosclerosis, Thrombosis, and Vascular Biology, 30, 802-808. http://dx.doi.org/10.1161/ATVBAHA.109.201681

[16] Mohammad, M.K., Morran, M., Slotterbeck, B., Leaman, D.W., Sun, Y., Grafenstein, H., Hong, S.C. and McInerney, M.F. (2006) Dysregulated Toll-like receptor expression and signaling in bone marrow-derived macrophages at the onset of diabetes in the non-obese diabetic mouse. International Immunology, 18, 1101-1113. http://dx.doi.org/10.1093/intimm/dxl045

[17] Creely, S.J., McTernan, P.G., Kusminski, C.M. et al. (2007) Lipo polysaccharide activates an innate immune system response in human adipose tissue in obesity and Type 2 diabetes. American Journal of Physiology: American Journal of Physiology, 292, 740-747. http://dx.doi.org/10.1152/ajpendo.00302.2006

[18] Song, M.J., Kim, K.H., Yoon, J.M. and Kim, J.B. (2006) Activation of Toll-like receptor 4 is associated with insulin resistance in adipocytes. Biochemical and Biophysical Research Communications, 346, 739-74521. http://dx.doi.org/10.1016/j.bbrc.2006.05.170

[19] Beutler, B. (2004) Inferences, questions and possibilities in Toll-like receptor signalling. Nature, 430, 257-263. http://dx.doi.org/10.1038/nature02761

[20] Li, H. and Sun, B. (2007) Toll-like receptor 4 in atherosclerosis. Journal of Cellular and Molecular Medicine, 11, 88-95. http://dx.doi.org/10.1111/j.1582-4934.2007.00011.x

[21] Dounousi, E., Koliousi, E., Papagianni, A., Ioannou, K., Zikou, X., Katopodis, K., Kelesidis, A., Tsakiris, D. and Siamopoulos, K.C. (2012) Mononuclear leukocyte apoptosis and inflammatory markers in patients with chronic kidney disease. American Journal of Nephrology, 36, 531-536. http://dx.doi.org/10.1159/000345352

[22] Lin, M., Yiu, W.H., Wu, H.J., Chan, L.Y., Leung, J.C., Au, W.S., Chan, K.W., Lai, K.N. and Tang, S.C. (2010) Tolllike receptor 4 promotes tubular inflammation in diabetic nephropathy. American Journal of Nephrology, 23, 86102.

[23] Dasu, M.R., Ramirez, S. and Isseroff, R.R. (2010) Tolllike receptors and diabetes: A therapeutic perspective. Clinical Science, 122, 203-214

[24] Devaraj, S., Tobias, P., Kasinath, B.S., Ramsamooj, R., Afify, A. and Jialal, I. (2011) Knockout of toll-like receptor-2 attenuates both the proinflammatory state of diabetes and incipient diabetic nephropathy. Arteriosclerosis, Thrombosis, and Vascular Biology, 31, 1796-1804. http://dx.doi.org/10.1161/ATVBAHA.111.228924 